\title{
REVITALISASI LEGENDA PAWANG TERNALEM SUKU KARO SEBAGAI BAHAN AJAR BAHASA INDONESIA
}

\author{
oleh \\ Sri Dinanta Beru Ginting ${ }^{1}$ (sridinanta_ginting@pnl.ac.id) \\ Wahyu Ningsih ${ }^{2}$ (wahyuningsih@unprimdn.ac.id) \\ Elnira Situmorang ${ }^{3}$ (elnirasitumorang97@gmail.com)
}

Universitas Prima Indonesia

\begin{abstract}
ABSTRAK-Penelitian ini dilakukan bertujuan untuk direvitalisasikan Legenda "Pawang Ternalem" menjadi bahan ajar. Revitalisasi dilakukan dengan cara menggambarkan secara sistematis, faktual, dan akurat dengan menggunakan kata-kata atau kalimat. Penelitian ini menggunakan metode deskriptif kualitatif. Teknik pengumpulan data dengan teknik simak bebas libat cakap. Data penelitian ini adalah data lisan berupa cerita rakyat legenda Pawang Ternalem. Sumber data dalam penelitian ini adalah masyarakat Karo. Teknik analisis data menggunakan analisis interaktif, yaitu: 1) reduksi, 2) penyajian data, dan 3) penarikan kesimpulan. Teknik validitas data yang digunakan triangulasi teori dan triangulasi sumber. Prosedur dalam penelitian ini, yaitu 1) perencanaan, 2) pelaksanaan, dan 3) peyusunan laporan. Hasil penelitian ini diketahui bentuk legenda "Pawang Ternalem" berasal dari suku Karo sebagai bahan ajar matapelajaran Bahasa Indonesia.
\end{abstract}

Kata kunci: revitalisasi, legenda "Pawang Ternalem"

\section{A. Pendahuluan}

Legenda sebagai karya sastra sering dianggap sebagai imajinasi oleh masyarakat Indonesia. Walaupun demikian, sastra pada dasarnya memiliki fungsi dalam bentuk sosial. Fungsi terebut dalam wujud penumbuhan nilai serta karakter pembaca sastra tersebut. Atas dasar itu, legenda yang merupakan bagian karya sastra perlu diberikan perhatian khusus. Perhatian dimaksudkan agar terbentuk karakter pembaca melalui karya sastra yang dibacanya.

Berkaitan dengan uraian sebelumnya, Danandjaja (2002:66) menjelaskan bahwa legenda merupakan cerita rakyat yang pada dasarnya dianggap sebagai kejadian yang pernah ada. Selanjutnya, Bruchac (dalam Nurgiyantoro, 2013:164) mengemukakan bahwa cerita rakyat (folklore) menjelaskan bahwa legenda sebagai sastra lisan merupakan jenis pengetahuan tradisional yang disampaikan secara lisan dalam sebuah masyarakat kecil yang terisolasi. Selanjutnya, sastra lisan tersebut diperoleh lewat nyanyian, permainan tradisional, cara dan tata bicara, serta adat-istiadat. Untuk itu, dapat dinyatakan legenda sebagai cerita rakyat merupakan pengetahuan dan karya tradisional untuk menceritakan kebudayaan di masyarakat. Hal tersebut diwujudkan dalam versi yang berbeda-beda dengan penyebarannya secara umum dilakukan secara lisan.

Berkaitan dengan uraian sebelumnya, legenda yang ada di Indonesia memiliki banyak kekhasan dari suatu daerah. Legenda-legenda tersebut sering kita peroleh di bangku sekolah atau pun disampaikan oleh orang tua. Namun, legenda di Sumatera Utara tidak terlalu dikenal seperti legenda di luar Sumatera. Pada dasarnya, ketidaktahuan tentang 
legenda Sumatera Utara disebabkan semakin turun keinginan masyarakat khususnya siswa terhadap membaca cerita rakyat di Sumatera Utara. Satu diantara legenda yang perlu dikaji adalah legenda "Pawang Ternalem" dari suku Karo di Sumatera Utara.

Legenda "Pawang Ternalem" pada dasarnya bercerita tentang asal usul pawang yang bermula dari anak laki-laki yang setelah kelahirannya kedua orang tuanya meninggal. Legenda ini hidup di daerah perbatasan Karo dan Dairi. Namun pada kenyataannya, banyak yang tidak mengetahui legenda tersebut. Jika dibiarkan, maka akan menjadi urgensi masalah berupa kehilangan kerarifan lokal di suku Karo. Berdasarkan urgensi masalah tersebut, perlu diteliti dengan seksama legenda tersebut. Bertitik tolak dari itu penelitian yang diangkat ini berjudul "Revitalisasi Legenda Pawang Ternalem suku Karo sebagai Bahan Ajar Bahasa Indonesia". Alasan dikaitkannya penelitian ini dengan pembelajaran bahasa karena kebutuhan bahan ajar bahasa Indonesia yang kurang banyak karena selama ini hanya berkisar pada legenda-legenda pada umumnya.

Berdasarkan uraian sebelumnya, berikut ini adalah tujuan dari penelitian ini. 1) Untuk mengetahui asal dan bentuk legenda "Pawang Ternalem" yang diuraikan masyarakat Karo. 2) Untuk mengetahui cara dilakukan revitalisasi legenda "Pawang Ternalem" sebagai bahan ajar Bahasa Indonesia.

\section{B. METODE PENELITIAN}

Sejalan dengan tujuan dari penelitian ini di dalam pendauluan, maka penelitian ini merupakan jenis penelitian deskriptif kualitatif. Hal tersebut disebabkan peneliti turun langsung ke

lapangan agar dapat dilakukan

pengumpulan data yang diperlukan dalam penelitian.

\section{Data dan Sumber Data}

Datanya adalah data lisan berupa Legenda suku Karo "Pawang Ternalem" yang terdapat di masyarakat Karo. Data tersebut berdasarakan bentuk legenda, fungsi legenda, dan maknanya. Sumber datanya adalah informan yang berasal dari masyarakat yang bersuku Karo.

\section{Lokasi dan Waktu Penelitian}

Lokasi penelitian yang dilakukan adalah di perbatasan Kabupaten Karo dan Dairi. Total waktu penelitian akan berlangsung selama 6 (enam) bulan mulai bulan Desember 2019 sampai dengan Agustus 2020.

\section{Prosedur Pengumpulan Data}

Metode yang digunakan yaitu metode simak dengan cara dilakukan simakan suatu bahasa. Adapun teknik yang digunakan yaitu teknik simak bebas Libat Cakap.

\section{Teknik Analisis Data}

Teknik analisis data menggunakan teknik analisis interaktif yang meliputi tiga komponen, yaitu reduksi data, penyajian data, dan penarikan simpulan (Miles dan Huberman, 2007:16-20). Adapun komponennya tersebut sebagai berikut.

1. Reduksi data (data reduction)

Data yang diperoleh dicatat yang selanjutnya dipilih dalam bentuk uraian yang terperinci. Data yang dipilih berkaitan dengan bentuk legenda suku Karo "Pawang Ternalem".

2. Penyajian data (data display)

Dilakukan penyusunan data yang

ada secara teratur atau terperinci. Dilakukan berdasarkan data yang telah direduksi. Data disusun berdasarkan dengan tujuan penelitian atau tujuan pelaksanaan. Selanjutnya, data dianalisis yang kemudian diperoleh deskripsi 
mengenai bentuk legenda suku Karo "Pawang Ternalem" dan transformasinya menjadi naskah drama.

3. Tahap penarikan simpulan dan verifikasi (conclution drawing)

Penarikan kesimpulan pada dasarnya berkaitan dengan penarikan simpulan mengenai bentuk legenda suku

Karo "Pawang Ternalem" dan transformasinya menjadi naskah drama. Setelah selesai disimpulkan maka hasil penelitian tersebut disusun sebagai bahan ajar.

\section{Teknik Validitas Data}

Validitas data merupakan jaminan atas kesimpulan penelitian. Hal tersebut sejalan dengan pernyataan Azwar (2012:105) bahwa kepercayaan hasil penelitian dapat diberikan pada kesimpulan penelitian tergantung akurasi dan kecermatan dari validitas dan reliabilitasnya. Teknik validitas data dapat dilakukan dengan triangulasi. Teknik triangulasi menurut Sutopo (2006:92) terdiri dari empat jenis triangulasi, yaitu 1) sumber, 2) metode, peneliti, dan teori. Teknik validitas data penilitian ini yang dilakukan adalah triangulasi teori dan sumber.

\section{Prosedur Penelitian}

a. Tahap perencanaan; dilakukan kegiatan penyusunan perumusan masalah, rancangan penelitian, serta penentuan cara untuk pengumpulan data.

b. Tahap pelaksanaan; dilakukan dua tahap, yaitu mengumpulkan data berdasarkan informan dari masyarakat karo agar diketahui bentuk legenda "Pawang Ternalem" secara lengkap. Tahappengelompokkanberupa pengelompokkan data berdasarkan rumusan masalah. Selanjutnya, tahap analisis data berdasarkan hasil wawancara dengan masyarakat karo sebagai informan. Terakhir, tahap penarikan kesimpulan dilakukan penyusunan jawaban dari rumusan masalah.

c. Tahap penyusunan laporan; Tahapan terakhir bagian ini adalah tahap penyusunan laporan. Tahap ini dilakukan setelah data dikumpulkan, telah dilakukan reduksi, telah dilakukan analisis, sampai telah dilakukan penyimpulan. Tahap ini dilakukan dengan pemindahan hasil penelitian ke dalam bentuk jurnal ilmiah.

\section{HASIL PENELITIAN}

Pada dasarnya legenda tidak dapat dilepaskan dari persoalan kesusastraan lisan. Sastra lisan tersebut diperoleh lewat nyanyian, permainan tradisional, cara dan tata bicara, serta adat-istiadat. Untuk itu, dapat dinyatakan legenda sebagai cerita rakyat merupakan pengetahuan dan karya tradisional untuk menceritakan kebudayaan di masyarakat. Hasil sastra lisan tersebut berkembang berdasarkan cerita-cerita rakyat yang diwariskan di suatu masyarakat.

Masyarakan dapat mengenali tradisi atau kebudayan yang diwariskan tersebut melalui sastra-sastra lisan, khususnya dalam bentuk legenda. Dengan demikan, hal tersebut dapat membuat

masyarakat untuk mengenal dan mengetahui radisi kebudayaan yang telah diwariskan secara turun-temurun. Hasil sastra lisan dapat diapresiasikan di dalam kehidupan. Secara khusus, setiap daerah memiliki cerita rakyat, terkhusus legenda sebagai bentuk pertinggal adanya cerita tersebut di masa lampau.

Berdasakan hal tersebut, legenda di suatu daerah harus terus direvitalisasi agar masyarakat dapat mengetahui bagaimana tradisi masyarakat pada masa lampau. Hal tersebut, berlaku pula pada legenda yang terdapat di Sumatera Utara. Untuk itu, dilakukan revitalisasi sastra lisan atau legenda di Sumatera Utara. 
Legenda yang direvitalisasi adalah legenda Pawang Ternalem dari suku Karo. Data yang diperoleh terkait revitalisasi legenda Pawang Ternalem Suku Karo ini berasal dari hasil wawancara. Bentuk legenda ini diperoleh berdasarkan proses pengumpulan data, analisis data, dan validitas data sehingga diperoleh cerita Legenda "Pawang Ternalem". Kategorisasi dalam mewawancarai informan, untuk memperoleh data antara lain secara garis besar adalah asal legenda, bentuk legenda, peninggalan sebagai penanda legenda, serta keadaan pawang ternalem saat ini.

\section{Bentuk Legenda "Pawang Ternalem"}

Legenda atau ceriata rakyat Pawang Ternalem menceritakan tentang anak yang bernama Darmawan Sinuraya. Anak tersebut tidak diakui oleh mayarakat. Hal tersebut disebabkan karena Sinaraya dilahirkan pada hari buruk. Saat Sinuraya dilahirkan, kedua orangtuanya meninggal yang menyebabkan ia tidak memiliki pengasuh.

Dilahirkan pada suatu hari yang buruk, seluruh masyarakat di Desa Liang Melas mempercayai bahwa Sinuraya suatu saat membawa sial. Kesialan yang diperoleh bukan hanya diterima oleh Sinuraya, tetapi juga kepada seluruh masyarakat kampong Liang Melas. Untuk itu, masyarakat Liang Melas sepakat untuk membunuhnya.

Kesepakatan agar Sinuraya dibunuh terhalang sementara oleh seorang warga yang mau mengurusnya.Warga tersebut berkeinginan mengasuh anak kecil itu walaupun selalu diberikan tekanan oleh warga Desa Liang Melas untuk menghilangkan nyawanya. Akhirnya, bibi (sebutan perempuan di suku Karo yang memiliki kekerabatan marga) juga tidak kuat terhadap tekanan masyarakat setempat. Masyarakat terus mengemukakan bahwa Sinuraya harus segera dibunuh.

Berbagai usaha dilakukan agar Sinuraya dapat dibunuh. Sinuraya pernah dimasukkan ke dalam kubangan lumpur yang terdapat banyak kerbau. Maksud perlakuan itu agar Sunuraya diinjak-injak oleh kerbau sehingga ia mati atau tewas. Tetapi, aneh nya tidak ada satu kerbau yang mau mendekatinya apalagi menginjaknya sehingga mati.

Usaha lain dilakukan oleh warga, Sinuraya pernah pula ditelantarkan di bawah rumah adat warga yang penuh babi. Maksud diletakkan di kolong yang terdapat babi agar babi dapat menyerang dan memakan tubuh dari Sinuraya. Anehnya lagi,babi-babi di kolong rumah itu merawat Sinuraya. Sinuraya tetap dapat tumbuh dan hidup dengan diberikan babibabi itu makanan. Bahkan Bibi yang merawatnya mengira Sinuraya atau Ternalem telah mati karena tidak ditemukan di dalam kolong itu.

Seiring semakin besar, Sinuraya atau Pawang Ternalem dibesarkan seorang Datuk di dalam hutan. Hal tersebut disebabkan Sinuraya dibawa oleh sekelompok Perlanja Sira yang membawanya ke sebuah hutan dekat Langkat. Di hutan itu, Sinuraya ditinggalkan kafilah pedagang. Tanpa sengaja, Sinuraya ditemukan oleh seorang sakti penguasa hutan bernama, Datuk Rubia Gande.

Pawang Ternalem dibesarkan oleh Datuk Rubia. Selain itu, ia juga diajarkan kemampuan kanuragaan dan bela diri. Ia saat itu telah mampu membela diri bahkan membela orang lain dari kejahatan. Suatu ketika, terjadi musibah di Desa Jenggi Kemawar. Seorang gadis yang 
bernama Beru Patimar (Adeline Bangun) yang merupakan putri kepala kampung, mengalami penyakit misterius. Berbagai usaha telah dilakukan ayahnya untuk menyembuhkan penyakit misteris itu.

Banyak dukun yang telah didatangkan untuk menyembuhkannya. Namun, tidak ada satu dukun pun yang mampu menyembuhkannya. Seluruh obat yang diberikan pun tidak dapat menyembuhkan Patimar. Tersiar kabar kepada ayahnya bahwa satu-satunya obat enyebutnya adalah madu. Madu itu menjadi pengharapan terakhir. Namun, madu itu hanya terdapat di pohon Tualang Simande Angin. Pohon itu adalah pohon keramat. Hal itu dibuktikan cerita bahwa tidak seorang pun mampu memanjatnya.

Atas dasar itu, Kepala kampung itu yang merupakan Bapak dari Beru Patimar mengadakan sayembara. Sayembara itu tidak tanggung-tanggung hadiah yang akan diberikan. Disiarkan kabar di dalam sayembara itu bahwa bagi yang berhasil memanjat Tualang Simande Angin dan berhasil mengambil madu untuk anak kesayangannya, selanjutnya ia akan menghadiahkan putrinya. Ia berjanji akan memberikan putrinya pada pemuda itu sebagai istri.

Kabar dari sayembara itu pun tersiar sampai kepada Datuk Rubia Gande. Pawang Ternalem selanjutnya ditugaskan Datuk Rubia untuk mengikuti sayembara dengan memanjat pohon itu untuk mendapatkan madu. Datuk Rubia yakin bahwa Siniraya atau Ternalem dapat mengambil madu dan membawanya kepada kepala kampong itu, akan tetapi, Datuk melakukan hal aneh kepada Ternalem. Sebelum berangkat, Ternalem diubah wajahnya oleh Datuk menjadi seperti babi. Awalnya Ternalem tidak memahami maksud dari perbuatan Datuk tersebut. Namun, Ternalem tetap mengikuti sayembara itu seperti perintah dari datuk.

Banyak warga yang telah berusaha mengambil madu itu, tetapi mereka semua tidak mampu mengambil madu. Bahkan mereka terserang penyakit atau

tewas. Kemudian, Ternalem mampu membawa madu dari pohon keramat itu. Ia berbisik kepada dirinya sendiri Bapa Nande biarkan aku kali ini memiliki penghormatan dari orang lain. Padahal, sebelum Ia banyak orang yang mati, dengan kata lain gagal memanjat pohon. Kemudian, madu itu diserahkan kepada kepala kampung sehingga Beru Patimar dapat disembuhkan penyakit misteriusnya.

Setelah mendapatkan madu itu, dalam keadaan wajah seperti babi, Ternalem menemua Beru Patimar. Beru Patimar

tentu menolak Ternalem saat mendengarkan kabar bahwa yang akan menjadi saudaranya adalah seorang pria yang dibesarkan oleh babi-babi dan hidup di hutan, saat menolak janjinya, Beru Patimar dikirim serangga oleh Ternalem agar menyengat tubuh Patimar. Singkat cerita, Beru Patimar tidak ingin memperoleh penyakit misterius lagi, Beru Petimar pun tetap memenuhi janjinya dengan menikahi siapa pun yang dapat membawa madu itu, Beru Patimar pun mau menikahi Ternalem yang mukanya seperti babi.

Pernikahan yang sempat ditolaknya akhirnya dilaksanakan di depan warga oleh penghulu. Hal itu dilakukan karena janji itu sudah terucap. Untuk itu, dari kisah Ternalem dan Beru Patimar diperoleh nilai-nilai kehidupan yang tersimpan secara pragmatik, yaitu: 1) kisah ini memberikan pelajaran tentang semangat dan tidak mudah menyerah. 2) Terus membangun kepercayaan diri 
walaupun dalam keadaan terhimpit dan berbagai rintangan. 3) Tidak boleh menyerah dalam keadaan apa pun. 4) Harus menepati janji yang telah terucap.

\section{Revitalisasi Legenda "Pawang Ternalem" dengan \\ Mentransformasi Legenda \\ "Pawang Ternalem" menjadi Naskah \\ Drama "Pawang Ternalem"}

Revitalisasi legenda "Pawang Ternalem" dilakukan dengan cara pentransformasian cerita tersebut dalam wujud naskah drama. Hal itu digunakan sebagai bahan ajar Bahasa Indonesia. Upaya tersebut diharapkan dapat terjadi penyebarluasan legenda ini dengan cepat. Langkah-langkah transformasi legenda menjadi naskah drama tersebut, yaitu.

\section{Penentuan tema}

Tema naskah drama Legenda "Pawang Ternalem", yaitu semangat juang.

2. Penentuan alur cerita

Alur cerita dari legenda "Pawang Ternalem" adalah menggunakan alur maju dengan lima tahapan cerita. Pertama, eksposisi (pengenalan); kelahiran tokoh utama, yaitu Sinuraya dilahirkan pada hari yang buruk. Kedua, komplikasi (pengenalan masalah); saat Ternalem dianggap pembawa sial sehingga ia tidak diterima masyarakat. Ketiga, klimaks (puncak masalah); tokoh dalam cerita dihadapkan dalam penentuan akhir atau kisah yang akan dialaminya, keberhasilan atau kegagalan biasanya menjadi penentuan nasib tokoh dalam cerita. Klimaks pada drama ini adalah saat Datuk Rubia Gande meminta Ternalem untuk memanjat pohon madu. Tugas itu dilakukan agar dapat menyembuhkan anak kepala kampung, yaitu; Beru Petimar. Keempat, resolusi (penurunan); resolusi pada drama ini dengan cara saat Ternalem mampu memanjar pohon madu dengan berwajah seperti babi. Kelima, penyelesain; dijelaskan kisah akhir atau nasib tokoh cerita dengan menjelaskan akhir cerita apakah bahagia, buruk, atau menggantung. Dalam cerita ini, kisah tokoh utama mendapatkan kebahagiaan, yaitu menikah dengan Beru Patimar.

3. Menyusun adegan

Drama ini disusun berdasarkan kisal aslinya. Drama ini disusun dalam lima babak

4. Membuat dialog antar tokoh Dialog tokoh disusun mulai saat Ternalem ditolak warga hingga ia menikah dengan Beru Patimar.

\section{PEMBAHASAN}

Penelitian tentang Legenda "Pawang Ternalem" terbentuk dari, akurasi dari bentuk legenda ini. Hal tersebut dimaksudkan dilakukan pengujian langsung kepada para informan serta penduduk sekitar Tanah Karo.

Penelitian ini pada dasarnya bertujuan untuk menggali kembali cerita "Pawang Ternalem" secara lengkap. Penelitian ini juga mengemukakan maksud dibalik adanya kisah di dalam legenda ini ditinjau secara pragmatik. Maksud diperoleh bahwa orang tua atau leluhur selalu mengajarkan semangat dan pantang menyerah walaupun dalam

keadaann apa pun. Selanjutnya, revitalisasi ini dilakukan dengan cara dijadikan sebagai bahan ajar Bahasa Indonesia dalam bentuk naskah drama. Hal serupa pernah dilakukan oleh penelitian relevan yaitu penelitian dari Prima, dkk (2019) yang berjudul "Transformasi Mite "Misteri Gang Keramat" Menjadi Naskah Drama Sebagai Bahan Ajar Bahasa Indonesia Siswa Kelas VIII SMP Muhammadiyah 05 
Medan Tahun Ajaran 2019/2020”. Penelitian ini bertujuan untuk menggali lebih dalam mite secara lengkap. Hasil dari mite ini ditransformasi ke naskah drama. Kesamaan terlihat dari hasil penelitian adalah menjadikan cerita rakyat menjadi sebuah naskah drama.

Berdasarkan hal tersebut, diharapkan dapat menjadi bahan ajar Bahasa Indonesia karena pada dasarnya pendidikan menjadi cara praktis dalam penyebarluasan tradisi atau cerita rakyat.

Hal tersebut dapat membuat berkurangnya kearifan lokal yang terkikis oleh zaman. Selanjutnya, hasil penelitian yang diperoleh peneliti, dapat dijadikan bahan ajar mata pelajaran Bahasa Indonesia pada siswa SMP kelas VIII. Hal itu dapat dilihat dari Silabus Bahasa Indonesia Kelas VIII K13 Revisi 2018 yang terdapat pembelajaran drama dan cerita rakyat.

\section{SIMPULAN}

Kesimpulan dari penelitian ini sebagai berikut. Pertama, legenda "Pawang Ternalem" berasal dari di Desa Liang Melas, Kabupaten Karo. Legenda Pawang Ternalem ini diperoleh peneliti berdasarkan proses pengumpulan data, analisis data, dan validitas data sehingga diperoleh cerita Legenda "Pawang Ternalem". Kedua, revitalisasi legenda "Pawang Ternalem" dilakukan denga cara mentransformasi legenda menjadi naskah drama "Pawang Ternalem".

\section{SARAN}

Dapat dilakukan pengembangan bahan ajar dan revitalisasi legendalegenda lain di Sumatera Utara. Hasil revitalisasi tersebut dapat disusun dalam sebuah buku sehingga dapat memiliki peninggalan keilmuan yang dapat digunakan dalam pertahanan kearifan lokal.

\section{REFERENSI}

Danandjaja, James. 1984. Folklor Indonesia: Ilmu Gosip, Dongeng, dan Lain-lain. Jakarta : PT Grafiti Pers.

Endraswara, Suwardi. 2013. Metodologi Penelitian Sastra: Epistemologi, Model, Teori, dan Aplikasi. Jakarta : PT Buku Seru.

Miles, Matthew B dan A. Michael Huberman. 2007. Analisis Data Kualitatif: Buku Sumber tentang Metode-metode Baru. Jakarta: UI Press.

Prima, N., Rahim, C., Ginting, R., \& Ginting, S. (2019, July 22). Transformasi Mite "Misteri Gang Keramat" Menjadi Naskah Drama Sebagai Bahan Ajar Bahasa Indonesia Siswa Kelas VIII SMP Muhammadiyah 05 Medan Tahun Ajaran 2019/2020. Jurnal BASATAKA, 2(1), 1-16. Retrieved from http://jurnal.pbsi.unibabpn.ac.id/index.php/

BASATAKA/article/view/41

Sudaryanto. 1993. Metode dan Aneka Teknis Analisis Bahasa. Yogyakarta: Duta Wacana University Press.

Sutopo, HB. 2006. Metodologi Penelitian

Kualitatif Dasar Teori dan Terapannya dalam Penelitian. Surakarta: UNS Press.. 